\title{
Research on the Way of Strengthening College Students Ideological and Political Education in Emergencies -Take COVID-19 Epidemic Prevention and Control as an Example
}

\author{
Chunlei Zhang \\ Heilongjiang Bayi Agricultural University, Heilongjiang Daqing, 163319 China
}

Keywords: COVID-19, college students, ideological and political education, emergencies

Abstract: In response to COVID-19, the Party Central Committee and all of universities or colleges around Chins have made important arrangements to strengthen and innovate students management during the pandemic. This aspect puts forward higher requirements for the effectiveness of ideological and political work in the college students' management. COVID-19 pandemic provides a new platform and indicates the direction of students' administration in colleges or universities. Active nursing intervention for college students and their families can effectively improve the psychological state of students, improve life satisfaction, improve the quality of life of students, and promote their better return to society, reflecting their own value. It has a certain reference value to reduce the incidence of disease complications, eliminate the anxieties, and promote the recovery of normal life.

\section{Introduction}

Ideological and political work is a science, and its scientific nature should not only be reflected in its guiding ideological level, but also be implemented in concrete student's administration work, especially for ideological education of college students. Strengthening and innovating social management is an important measure to improve the scientific level of social management in China, and it is also the only way to actively build a socialist harmonious society. Strengthening and innovating social management work in college campus is inseparable from the effective functioning of ideological and political work, including education, coordination, psychology, integration, and incentives. Ideological and political work is also inseparable from the important practical platform of social management. Ideological and political work must further enhance the effectiveness and demonstrate the value of the times in the social management practice of students' management during the COVID-19 pandemic prevention.

\section{The Negative Impact of Mass Herd Psychology on Crisis Public Opinion}

With the adjustment of the national economic interests, people's ideology and concepts are also 
changing. The credibility of the government is gradually declining, and the students and their family members sense of happiness in the cities they live in is continually decreasing. The lack of credibility of the government stems from the fact that the grassroots government cannot properly deal with self-media. Since the media has a strong accumulation and diffusion effect on negative news, it is easy to gather scattered issues into focus events, expand local issues into group events, and ordinary issues evolve into political events, easily creating irrational emotions in society.

It can be seen that measures taken by the government on certain incidents continue to be handled by the government in the past, and administrative penalties are imposed on staff directly involved in the incidents. But for the family members who lost their loved ones, they did not get the humane care and emotional comfort from the government. This incident has erupted, and the news media and online media are competing to broadcast and reprint. Mass netizens are also eager to express their opinions. From this perspective, perhaps each college student has their own views, but it is not. When each of the masses expresses their views, students in colleges have more or less read the statements made by other masses before that. Under their influence, they are likely to deviate from their own views. One is still the case, if there is too much speech, it will naturally produce herd mentality. And the negative impact on the incident also occurred.

Once a crisis event has a negative impact, it would be difficult for college students to try to eliminate it. Because the conclusion of the matter has already reached the conclusion of the coffin in the hearts of the masses, and then trying to reverse the truth of the matter requires more time and energy. This will greatly reduce the government's and universities' ability to educate students with the effortless endeavor.

\section{Enhance the early warning awareness of relevant subjects}

Improve the early warning awareness and responsibility awareness of universities leaders. Early warning decision-making is the process of formulating countermeasures and implementation plans for the collected information in combination with decision-making norms and actual conditions. In the process of college early warning, policy makers play an important role, and the lack of rationality and scientific decision-making will inevitably cause serious adverse consequences. The purpose of the college is to focus on the safety and interests of students, and the college's decision should be based on the safety and interests of the students. However, in reality, there is still a phenomenon of lack of supervision and some students disobeyed the social rules and public morality. Therefore, such acts should be severely cracked down to educate the college students. Colleges can arrange for decision makers to regularly learn relevant knowledge to improve management capabilities; decision makers can organize training or special practical investigations from their own perspectives and strive to improve the scientificity and rationality of decision-making.

Increase students' attention. In real life, due to the lack of attention by students, inadequate publicity and the lack of scientific understanding of the public themselves, the undesirable consequences of harm are unpredictable. To this end, colleges must do supervise in students thoughts and related information. On the one hand, colleges can be arranged to carry out emergency drills to prevent the emergency online; on the other hand, professionals can be arranged for lectures about pandemic prevention, and a special bulletin board and common sense booklet can be set to enhance by various ways taken by colleges. The colleges attach great importance to the early warning of emergencies and reduces the major losses caused by the crisis.

\section{Focus of work in emergencies}

The results of COVID-19 epidemic prevention and control have consolidated and improved, and 
local epidemic situation has been basically controlled, but the risk of overseas epidemic situation input continues to increase. As educators in colleges must accurately grasp the situation characteristics of the epidemic prevention and control change from static to dynamic, and from emergency to normal, and follow the target strategy of "external defense input, internal defense rebound" The basic requirements for precise prevention and control in the colleges are adjusted according to local conditions, time, and circumstances, and innovative, precise, differentiated, diversified, digital, and high-efficiency prevention and control measures are implemented.

The current main tasks are: implement precise prevention and control strategies in colleges after students back , strictly implement the "four early" measures, strengthen the normalization of combat readiness construction, expand the scope of detection, improve the closed-loop management of the input of epidemic recovery situations, and properly do the prevention and control of epidemic situations in public places. Strengthening the management of students daily management, services, speed up the restoration of normal medical order, strongly support scientific research, and continue to develop patriotism Health campaign.

Nucleic acid testing should be performed for each students come back from their cities, especially for experienced history of overseas, and people with a history of high-risk areas; educate students to carry out civilized and hygienic habits promotion actions focusing on the prohibition of spitting, focusing on the "four after" Interventions for epidemic prevention and control, comprehensive environmental remediation actions focusing on campus environmental hygiene and cleanliness, standardization construction operations on classrooms, dormitory and research sites focusing on reducing vector infectious diseases, and carrying out Six major actions, including health knowledge popularization actions focusing on knowledge control, continue to consolidate the results of epidemic prevention and control, and help to comprehensively win the province's COVID-19 epidemic prevention battle.

\section{Next step of the work plan}

All college students must learn from the lessons of COVID-19 pandemic, draw inferences from others, and draw lessons from it. We must stand at the height of safeguarding the people's health rights and interests, establish a bottom-line awareness, strengthen social responsibilities, and avoid the recurrence of such epidemics.

One is to have a profound understanding of the severe situation facing the prevention and control of the epidemic situation. All students should attach great importance to COVID-19 epidemic prevention and control, further enhance their sense of responsibility and urgency, tighten the string of epidemic prevention and control, and pay close attention to the normalization of epidemic prevention and control. In particular, alerting responsibilities as a devotee should always pay attention to the importation of epidemic situations, and strictly prevent the spread of local infections, the occurrence of related cases or even clustered epidemic situations.

The second is to implement the requirements for normalization of epidemic prevention and control. All students should improve and implement a normalized prevention and control mechanism for timely detection, rapid disposal, precise control, and effective psychological and disease treatment, so that the relevant epidemic situations can be discovered and put out together. It is necessary to further implement the requirements of early detection, early reporting, early isolation, and early treatment, and do a good job in the closed-loop management of the entire chain from "overseas" to "national gate" to "home gate". Strengthen student's management, reduce gathering, guide scientific prevention and control, and reduce community communication risks.

The third is that college should improve the abilities of scientific management. Based on the COVID-19 pandemic research outcomes, services provided by the disease control agencies, 
governments, colleges or other communities should further expand the scope of service, to carry out social construction, and enable them to quickly reach put of the epidemic anxiety. Meanwhile, college should cooperate with local health organizations strengthen the guidance and management of students' health records, strengthen personnel training, ensure the management efficiency.

Fourth, continue to lay a solid foundation for colleges' infection prevention and control in institutions. All colleges supervisors should regard the management of students' prevention and control as an important part of winning the battle against epidemic prevention and control, and provide support in policies, funds, manpower, and materials. Colleges and educators are mainly responsible for comrades to personally arrange related work to ensure that the students infection prevention and control management system and work requirements are in place. Based on the preliminary work, all institutions should carry out a "look back" activity on the prevention, pay close attention to the inspection of loopholes, fill in shortcomings, establish rectification accounts, and implement number management. The students' affairs administrative department should strengthen guidance and supervision, and further strengthen various measures for prevention and control of nosocomial infections on campus.

\section{Conclusion}

In such a special period, educators in colleges should communicate more with the students at home, especially for the infections or isolations. When the students management effect on the condition does not meet its expected value, or there is an act of disappointing, the educators must explain the students' questions in a timely manner, stabilize the student's emotions, and prevent the increase of psychological burden due to the influence of bad emotions. Among them, the staff in colleges must adopt different methods of psychological counseling for the students 'bad emotions. Increase the self-esteem and self-confidence of them.

\section{References}

[1] Yan Wenbo, Dai Shengnan. The system advantage is the magic weapon to win the epidemic prevention and control [EB / OL]. (2020-02-19). Http://theory.people.com.cn/BIG5/n1/ 2020/0219 / c40531-31594828.html.

[2] Jiang Hui. Converting political advantages into epidemic prevention and control advantages [N]. People's Daily, 2020-02-20 (9).

[3] Zhu Zhiping. Research on Social Security Risk Governance of Super Large Cities under the New Situation [J]. Practice and Theory of Special Zones, 2018 (5): 84-89.

[4] Gong Zhigang. Social risk prevention and control and strategic transformation of policing during the historical period [J]. Public Security Research, 2018 (1): 55-77. 